\title{
Studies on antimicrobial activity, in vitro, of Physalis angulata $L$. (Solanaceae) fraction and physalin B bringing out the importance of assay determination
}

\author{
Melissa TG Silva/*/+ , Sonia M Simas**, Terezinha G FM Batista**, Paola Cardarelli***, \\ Therezinha CB Tomassini*
}

\author{
Programa de Pós Graduação em Vigilância Sanitária *Laboratório de Química de Produtos Naturais, Far-Manguinhos \\ **Laboratório de Controle Microbiológico de Antibióticos ***Laboratório de Biologia Molecular-INCQS-Fiocruz, Av. Brasil \\ 4365, 21040-900 Rio de Janeiro, RJ, Brasil
}

Complex physalin metabolites present in the capsules of the fruit of Physalis angulata L. have been isolated and submitted to a series of assays of antimicrobial activity against Pseudomonas aeruginosa ATCC 27853, Staphylococcus aureus ATCC 29213, S. aureus ATCC 25923, S. aureus ATCC 6538P, Neisseria gonorrhoeae ATCC 49226, Escherichia coli ATCC 8739; E. coli ATCC 25922, Candida albicans ATCC 10231 applying different methodologies such as: bioautography, dilution broth, dilution agar, and agar diffusion techniques. A mixture of physalins (pool) containing physalins B, D, F, G inhibit S. aureus ATCC 29213, S. aureus ATCC 25923, S. aureus ATCC 6538P, and $\mathrm{N}$. gonorrhoeae ATCC 49226 at a concentration of $200 \mathrm{mg} / \mu \mathrm{l}$, using agar dilution assays. The mixture was inactive against P. aeruginosa ATCC27853, E. coli ATCC 8739; E. coli ATCC 25922, C. albicans ATCC 10231 when applying bioautography assays. Physalin $B(200 \mu \mathrm{g} / \mathrm{ml})$ by the agar diffusion assay inhibited $\mathrm{S}$. aureus ATCC $6538 \mathrm{P}$ by \pm 85\%; and may be considered responsible for the antimicrobial activity.

Key words: Physalis angulata L. - antimicrobial methods - physalins

Physalis is an important genus of the Solanaceae family. Most of the species are herbaceous annuals or perennials, native to tropical North and South America. Some species have edible fruits and the tea of their roots is considered in popular medicine. The medical uses of Physalis are numerous: a wide variety of species are used for asthma, urinary problems, rheumatism, and tumors. Their anti-inflammatory and anti-spasmodic properties are also known.

Ray and Gupta (1994) and Tomassini et al. (2000) report some data on therapeutic applications and describe the pharmacological activity of the Physalis species as anti-parasitic, anti-viral, and anti-neoplasic.

Trypanocidal activity was described by Freiburhaus et al. (1996) for P. angulata L. dichloromethane and ether extracts. Acetone, ethyl acetate, ethanolic extracts from leaves, stems, and roots of the specimen were assayed against Biomphalaria tenagophila yielding positive results for molluscicidal activity (Dos Santos 2003).

Antimicrobial activity was described by Ongulana and Ramstad (1975) for methanol/water extracts of P. angulata against Bacillus subtilis. Cáceres et al. (1995) reported the results of the antimicrobial tests with the ethanolic extract leaves of Neisseria gonorrhoeae in agreement with the reported popular use in Guatemala. Aqueous and ethanolic extracts of $P$. angulata inhibited the growth of

Financial support: Far-Manguinhos-Fiocruz

${ }^{+}$Corresponding author. E-mail: melissa@far.fiocruz.br, meltgomes@terra.com.br

Received 16 June 2005

Accepted 10 November 2005
Staphylococcus aureus and Escherichia coli (Sanches et al. 1997, Silva et al. 1999).

Pietro et al. (2000) described the tuberculostatic activity of $P$. angulata chloroform extracts from epigeal parts against Mycobacterium tuberculosis, M. avium, M. kansaii, M. malmoense, and M. intracellulare.

Januário et al. (2003) reported activity against $M$. tuberculosis for physalins B and D.

Physalin F isolated from $P$. angulata ethanolic extract (Chiang et al. 1993) shows a potent antineoplasic activity. Soares et al. (2003) described the immunosuppressive activity of physalins B, F and G extracted from the stems of $P$. angulata $\mathrm{L}$.

The continuous development of antibiotic resistance of pathogenic microorganisms and particularly of Streptococcus pneumoniae to penicillin (PRSP), Staphylococcus aureus to methicillin (MRSA), and Enterococcus to vancomycin (VRE) is a major health concern worldwide with economic, social and political implications.

The screening of plant materials and their isolated substances for new antimicrobial compounds represent an important potential source for new effective medicines.

Several techniques are routinely available to test antimicrobial properties, among which, the most popular are the following:

Agar diffusion technique - Known as the Kirby-Bauer method, this assay was standardized by Bauer et al. in 1966. It is the test, which is most widely used in clinical practice and is recommended by Clinical and Laboratory Standards Institute (CLSI 2001).

The method measures microbial growth inhibition at the surface of an inoculate medium around a paper disk impregnated with the antimicrobial substance at a standard concentration. The result may show, or not, the pres- 
ence of an inhibition zone around the paper disk, the diameter of this zone being a good indicator of the antibiotic activity.

Bioautography - This assay is a variation of the agar diffusion methodology. The sample to be analyzed is transferred from the chromatographic adsorbent to the inoculated agar. The spots containing the substances are visualized using microbial indicators (tetrazolium salts) as a growth detector of dehydrogenase activity (Kline \& Golab 1965, Rahalison et al. 1994, Nostro 2000).

Dilution tests - These can be applied in solid (agar dilution) or liquid (micro and macrodilution broth method) media. The results obtained allow a quantitative estimate of antimicrobial activity. Several dilutions of the antimicrobial substance are incorporated to the liquid or solid media to determine the minimal inhibitory concentration (MIC). MIC is the smallest concentration of the antimicrobial agent, which is capable of inhibiting the growth of the microorganism in vitro. These data are important to determine the optimal dosage as well as the correct administration route of the antimicrobial substance in therapy.

The present study deals with the antimicrobial activity of Physalin B and enriched physalin fractions (mixture of $\mathrm{B}, \mathrm{D}, \mathrm{F}$, and $\mathrm{G}$ physalins) against pathogenic gram positive and gram negative microorganisms in a search for a new antibiotic, as well as to find the best conditions for antimicrobial determination.

\section{MATERIALS AND METHODS}

Plant collection - P. angulata L. was collected in Belém, Pará, North of Brazil and a voucher (RFA\# 23907/ 8) was deposited at the Botanical Department of the Universidade Federal do Rio de Janeiro.

Plant extraction, fractioning, and identification Dried and powdered capsules $(1000 \mathrm{~g})$ from the fruits of $P$. angulata $\mathrm{L}$. were extracted exhaustively with hot ethanol (Soxhlet) to yield, after evaporation under reduced pressure, $101 \mathrm{~g}$ of crude material. This ethanolic extract was treated with lead acetate under the experimental conditions described by Tomassini et al. (1999) to yield $9.7 \mathrm{~g}$ of a pool of physalins from which pure physalin B $(58 \mathrm{mg})$ was purified by chromatography on silica gel with elution by hexane ethyl acetate 30:70. Physalin B was identified by spectroscopic analyses and by comparison with literature data. The pool of physalins and physalin B were obtained from the $P$. angulata ethanolic capsule extract in 9.6 and $1.2 \%$ yield respectively.

Microorganisms - The microorganisms used in the antimicrobial assay were $C$. albicans ATCC 10231, E. coli ATCC 8739, E. coli ATCC 25922, N. gonorrhoeae ATCC 49226, P. aeruginosa ATCC 27853, S. aureus ATCC 29213, S. aureus ATCC 25923, S. aureus ATCC 6538P. These microorganisms were obtained from the Instituto Nacional de Controle da Qualidade e Saúde (INCQS) Fiocruz, Rio de Janeiro, Brazil.

Antimicrobial tests were performed by bioautography, broth dilution, agar dilution, and agar diffusion procedures.
Bioautography - Tests were performed with $100 \mu \mathrm{g} / \mathrm{ml}$ of physalin pool methanolic solutions at: $1000 \mu \mathrm{g} / \mathrm{ml}, 2500$ $\mu \mathrm{g} / \mathrm{ml}, 5000 \mu \mathrm{g} / \mathrm{ml}$ respectively. Each aliquot $(100 \mu \mathrm{l})$ was applied over a chromatosheet of Silica gel $60 \mathrm{~F}_{254}$ followed by elution with a system of ethyl acetate/hexane (7:3) and air-drying. The chromatogram was placed on a Petri dish and inoculated agar was distributed over the chromatogram inside the Petri dish with $40 \mathrm{ml}$ of an appropriate culture medium such as Iso-sensitest agar inoculated with $0.5 \%$ from a standardized suspension for $S$. aureus and P. aeruginosa, $0.7 \%$ for E. coli, and Sabouraud agar $1 \%$ for a standardized suspension of $C$. albicans. The standardized suspensions of microorganisms were prepared by using a spectrophotometer at $25 \% \mathrm{~T}-580$ nm (FDA 1991). For $N$. gonorrhoeae the chromatogram was deposited on $40 \mathrm{ml}$ of solid GC agar enriched with $1 \%$ Isovitalex sowed with a culture of $N$. gonorrhoeae inoculum adjusted to the $0.5 \mathrm{McF}$ arland turbidity standards (Bauer 1966, CLSI 1993). All plates were incubated at $35^{\circ} \mathrm{C}$ $\left(29^{\circ} \mathrm{C}\right.$ for C.albicans) for $18 \mathrm{~h}$, with $5-8 \% \mathrm{CO}_{2}$ for $N$. gonorrhoeae and in an ambient air incubator for the others. The inhibition zones were visualized with $2.5 \%$ methylthiazolyltetrazolium (MTT) solution to detect the dehydrogenase activity. This test was performed in duplicate.

Dilution methods - Both dilutions methods, i.e, microdilution broth and agar dilution, were carried out by following the procedure outlined by CLSI $(1993,2001)$ using physalin pool concentrations of $1600 \mu \mathrm{g} / \mathrm{ml}, 800$ $\mu \mathrm{g} / \mathrm{ml}, 400 \mu \mathrm{g} / \mathrm{ml}, 200 \mu \mathrm{g} / \mathrm{ml}, 100 \mu \mathrm{g} / \mathrm{ml}, 50 \mu \mathrm{g} / \mathrm{ml}, 25 \mu \mathrm{g} / \mathrm{ml}$, $12.5 \mu \mathrm{g} / \mathrm{ml}, 6.3 \mu \mathrm{g} / \mathrm{ml}$, and $3.1 \mu \mathrm{g} / \mathrm{ml}$.

Microdilution trays were incubated at $35^{\circ} \mathrm{C}$ for $18 \mathrm{~h}$ in an ambient air incubator. Controls were prepared: one without physalins and the other without the microorganism used in the assay. This method was applied only for the aerobic microorganisms.

The agar dilution technique was used for aerobic microorganisms and fastidious microorganisms. Controls with methanol/water 100, 50, 25, and 12\% were used for all microorganisms. The plates were incubated at $35^{\circ} \mathrm{C}$ for 18 $\mathrm{h}$ in an ambient air incubator for aerobic pathogens at $35^{\circ} \mathrm{C}$ for $18 \mathrm{~h}$, with 5-8\% $\mathrm{CO}_{2}$ (for fastidious microorganism $N$. gonorrhoeae). All tests were performed six times.

Agar diffusion - Tests were carried out according to the Farmacopéia Brasileira (1988) and USP XXIII Pharmacopoeia (1995) procedures using disks impregnated with the following amounts applied in methanol of the physalin pool: $1600 \mu \mathrm{g}, 800 \mu \mathrm{g}, 400 \mu \mathrm{g}, 200 \mu \mathrm{g}, 100 \mu \mathrm{g}$, and $50 \mu \mathrm{g}$. Based on the linearity range determination and values of MIC obtained from the physalins pool, the physalin B concentrations assayed were $400 \mu \mathrm{g}, 200 \mu \mathrm{g}$, and $100 \mu \mathrm{g}$. The plates were incubated at $35^{\circ} \mathrm{C}$ for $18 \mathrm{~h}$ in an ambient air incubator. The zone diameters were measured with the Fisher Lilly apparatus. The tests were performed nine times.

\section{RESULTS AND DISCUSSION}

The bioautography screening method was the first method applied to detect the microorganism sensitivity to physalins. The bioautography involved a solvent that 
completely dissolved the physalin pool and pure physalin B. Bioautography as described, with fully dissolved physalins was reproducible at all concentrations used.

After detection with MTT, C. albicans ATCC 10231, E. coli ATCC 8739, E. coli ATCC 25922, and P. aeruginosa ATCC 27853 did not show sensitivity to the physalin pool while $N$. gonorrhoeae ATCC 49226, S. aureus ATCC 29213, S. aureus ATCC 25923, S. aureus ATCC 6538P strains showed positive results (Fig. 1).
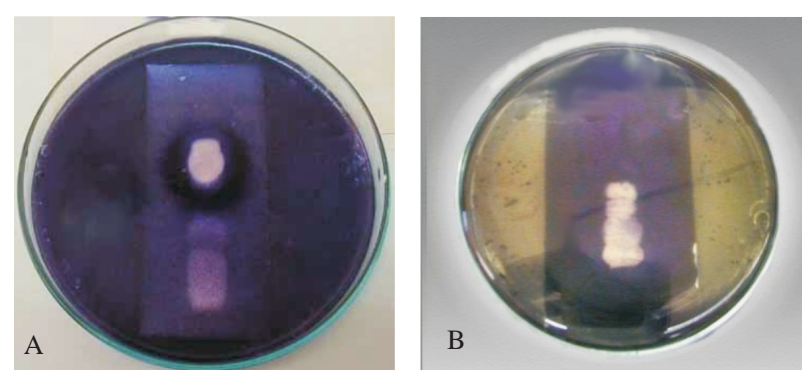

Fig 1: bioautography-physalin pool assays using Staphylococcus aureus ATCC 6538P (A) and Neisseria gonorrhoeae ATCC 49226 (B) at $100 \mu \mathrm{g} / \mathrm{ml}$ respectively.

The MIC for the physalin pool was based on the lowest concentration at which a positive effect was detected in bioautography assays.

Due to the insolubility of physalins in water or in aqueous $1.5 \%$ dimethylsulfoxide, it was not possible to use the microdilution broth technique.

Table I shows the MIC values for $N$. gonorrhoeae ATCC 49226, S. aureus ATCC 29213, S. aureus ATCC 25923, S. aureus ATCC 6538P for the physalin pool when applying the agar dilution assay. This technique is more versatile than microdilution broth due to the good stability of physalins in agar. The agar dilution assay suffers less from contamination and allows the determination of MIC for several microorganisms at the same time.

In agreement with the USP XXIII Pharmacopoeia (1995) and the FDA Code (1991), protocols recommended for the study of antibiotic potency against the strain of S. aureus ATCC 6538P were used for the potency determination of physalin applying the agar diffusion technique.

Table II shows the average values for inhibitory zones obtained after nine replications. Based on these results, it was possible to establish the linearity range presented in Fig 2. Table III shows the results of a comparative study

\section{TABLE I}

Minimum inhibitory concentrations (MIC) of physalin pool from Physalis angulata L. by agar dilution technique

\begin{tabular}{lccc}
\hline & \multicolumn{3}{c}{ MIC $(\mu \mathrm{g} / \mathrm{ml})$} \\
\cline { 2 - 4 } Microorganisms & 50 & 90 & Range \\
\hline Staphylococcus aureus ATCC 6538P & 100 & 200 & $3.1-1600$ \\
Staphylococcus aureus ATCC 25923 & 100 & 200 & $3.1-1600$ \\
Staphylococcus aureus ATCC 29213 & 100 & 200 & $3.1-1600$ \\
Neisseria gonorrhoeae ATCC 49226 & 100 & 200 & $3.1-1600$ \\
\hline
\end{tabular}

TABLE II

The relationship between inhibition zone diameters and minimal inhibitory concentration of the physalin pool applying agar diffusion technique for Staphylococcus aureus ATCC 6538P

\begin{tabular}{lcr}
\hline \multirow{2}{*}{$\begin{array}{l}\text { Physalin pool } \\
\text { concentrations }(\mu \mathrm{g})\end{array}$} & \multicolumn{2}{c}{ Zone diameters $(\mathrm{mm})$} \\
\cline { 2 - 3 } & Median & Range \\
\hline 50 & 8.2 & $8.0-8.4$ \\
100 & 9.1 & $8.8-9.2$ \\
200 & 10.2 & $9.8-11.8$ \\
400 & 11.0 & $10.8-12.0$ \\
800 & 11.2 & $11.0-12.0$ \\
1600 & 11.0 & $10.6-12.0$ \\
\hline
\end{tabular}

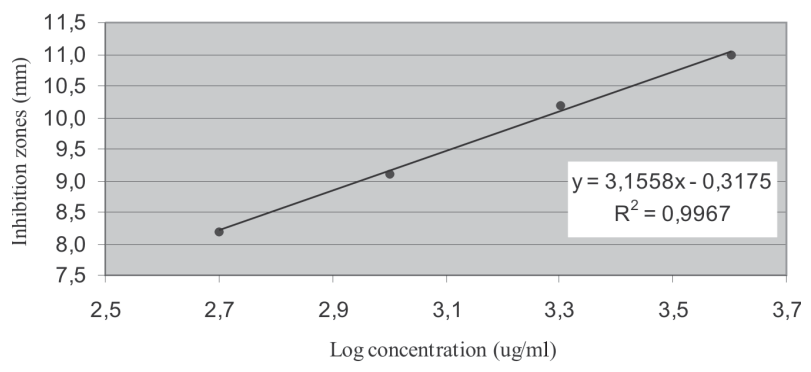

Fig 2: inhibitory zone $(\mathrm{mm}) \times \log$ concentrations $(\mu \mathrm{g} / \mathrm{ml})$.

\section{TABLE III}

Comparative study between the physalin pool and physalin B at three concentrations by the agar diffusion technique over Staphylococcus aureus ATCC 6538P

\begin{tabular}{lcrc}
\hline & \multicolumn{2}{c}{ Zone diameters $(\mathrm{mm})$} \\
\cline { 3 - 4 } Samples & Concentrations $(\mu \mathrm{g})$ & Median & Range \\
\hline Physalin pool & 100 & 9.0 & $7.0-9.2$ \\
& 200 & 10.4 & $8.0-11.0$ \\
Physalin B & 400 & 10.7 & $9.4-11.0$ \\
& 100 & 7.4 & $6.0-8.0$ \\
& 200 & 9.2 & $6.2-10.0$ \\
& 400 & 10.0 & $8.6-11.4$ \\
\hline
\end{tabular}

between physalin pool and physalin B at three different concentrations using the agar diffusion technique. This result shows that, at the concentration of $200 \mu \mathrm{g} / \mathrm{ml}$, pure physalin B exhibited $\pm 85 \%$ of the inhibitory zone observed with the total pool of physalins, at the same concentration.

In the bioautography assays, the physalin pool and physalin B did not inhibit $C$. albicans, P. aeruginosa or $E$. coli strains but did reveal efficacy against $N$. gonorrhoeae and $S$. aureus.

The physalin pool at $200 \mu \mathrm{g} / \mathrm{ml}$ yielded $100 \%$ inhibition for S. aureus ATCC 29213, S. aureus ATCC 25923, S. aureus ATCC 6538P, and N. gonorrhoeae ATCC 49226, in agar dilution tests.

The above results point to the following conclusions: (a) the bioautography assay is a practical, reproducible test and easy to perform; (b) the agar dilution technique 
is more versatile than the broth dilution assay and does not present the problems encountered with this latter assay with the sample solution, contamination and MIC determination; (c) the agar diffusion technique can be used only for pure substances because when it is applied to mixtures containing constituents, which exhibit different diffusion factors, and, thus the results may be unreliable; (d) the methods related here-in permit the choice of the best tool for determination of the antimicrobial constituents from plant material.

\section{ACKNOWLEDGEMENTS}

To the National Institute of Health and Control for technical support.

\section{REFERENCES}

Bauer AW, Kirby MM, Sherris JC, Turck M 1966. Antibiotic susceptibility testing by a standardized single disk method. Am J Clinl Pathol 45: 493-496.

Cáceres A, Menéndez H, Méndez E, Cohobón E, Samayoa BE, Jauregui E, Peralta E, Carrillo G 1995. Antigonorrhoeal activity of plants used in Guatemala for the treatment of sexually transmitted diseases. J Ethnopharmacol 48: 8588 .

Chiang HC, Jaw SM, Chen CF, Kan WS 1993. Antitumor agent, physalin F from Physalis angulata L. Anticancer Res 12: 837-844.

CLSI-Clinical and Laboratory Standards Institute 1993. Methods for dilution antimicrobial susceptibility tests for bacterial that grow aerobically, 3rd ed., Approved Standard (M7A3), Wayne, PA.

CLSI-Clinical and Laboratory Standards Institute 2001. Performance standards for antimicrobial susceptibility testing 11th ed., Information supplement (M2-A7 e M7-A5), Wayne, PA.

Dos Santos JAA, Ribeiro IM, Drummond D, Silva MTG, Morais ZB, Tomassini TCB 2003. Mollusccidal activity of Physalis angulata 1 . extracts and fractions on Biomphalaria tenagophila (d' Orbigny, 1835) under laboratory conditions. Mem Inst Oswaldo Cruz 98: 425-428.

Farmacopéia Brasileira 1988. Ensaio Microbiológico de Antibióticos, $4^{\mathrm{a}}$ ed., São Paulo, v.5.2.1.7.

FDA-Food and Drug Administration 1991. Code of Federal Regulation: Food and Drugs - CFR: 21 parts, 300-499, Washington DC: Office of the Federal Register National Archives and Records Administration as a Special Edition of the Federal Register, p. 328-345.

Freiburhaus F, Kaminstry R, Nkunya NHH, Brun R 1996. Evaluation of African medicinal plants for their "in vitro" trypanocidal activity. J Ethnopharmacol 55: 1-11.
Januário AH, Rodrigues Filho E, Pietro RCLR, Kashima DN, Sato DN, França SC 2002. Antimycobacterial physalins from Physalis angulata L. (Solanaceae). Phytother Res 16: 445-448.

Kline RM, Golab T 1965. A simple technique in developing thin-layer bioautography. J Chromatogr 18: 409-411.

Nostro A 2000. Extraction methods and bioautography for evaluation of medicinal plant antimicrobial activity. Lett Appl Microbiol 30: 379-384.

Ogunlana EO, Ramstad E 1975. Investigations into the antibacterial activities of local plants of Nigeria. Planta Med 27: 354-360.

Pietro RCLR, Kashima S, Sato DN, Januário AH, França SC 2000. In vitro antimycobacterial activities of Physalis angulata L. Phytomedicine 7: 335-338.

Rahalison L, Hamburguer M, Monod M, Hostettmann K 1994. Antifungal tests phytochemical investigations: comparison of bioautographic methods using phytopathogenic and human pathogenic fungi. Planta Med 60: 41-44.

Ray AB, Gupta M 1994. Withasteroids, a growing group of naturally occurring steroidal lactones. In W Herz, GW Kirby, RE Moore, W Steglich, CH Tamm (eds), Progress in the Chemistry of Organic Natural Products, SpringerVerlag, Austria, p. 2-13 and 56-58.

Sanches EG, Silva MTG, Ribeiro IM, Tomassini TCB 1997. Evaluation of the antibacterial activity of Physalis angulata L. extracts. Boll Chim Farm 2: 136.

Silva MTG, Marques GH, Ribeiro IM, Sanches EG, Tomassini TCB 1999. Evaluation of the bacteria inhibitory profile between native Belém do Pará and Rio de Janeiro cultivated P.angulata L. species against S.aureus, E.coli, K. pneumoniae. Boll Chim Farm 2: 138.

Soares MBP, Bellintani MC, Ribeiro I M, Tomassini TCB, Dos Santos RR 2003. Inhibition of macrophage activation and lipopolysaccharide-induced death by seco-steroids purified from Physalis angulata L. Europ J Pharmacol 459: 107112.

Tomassini TCB, Barbi NS, Ribeiro IM, Xavier, DCD, inventors; Fiocruz, Far-Manguinhos assignee 1999. Processo de isolamento de fisalinas a partir de plantas e composições farmacêuticas com atividade anti-protozoa contendo fisalinas. Brazilian patent BR 9904635, July 23, Int. Cl 09/ 417779.

Tomassini TCB, Barbi NS, Ribeiro IM, Xavier DCD 2000. Gênero Physalis - Uma revisão sobre vitaesteróides. Química Nova 23: 47-57.

USP-United States Pharmacopoeia 1995. Biological tests and assays. antibiotics-microbial assays, 23rd ed., United States Pharmacopoeia Convention, INC. 1690-1696, Twinbrook Parkway, Rockville, MD. 